
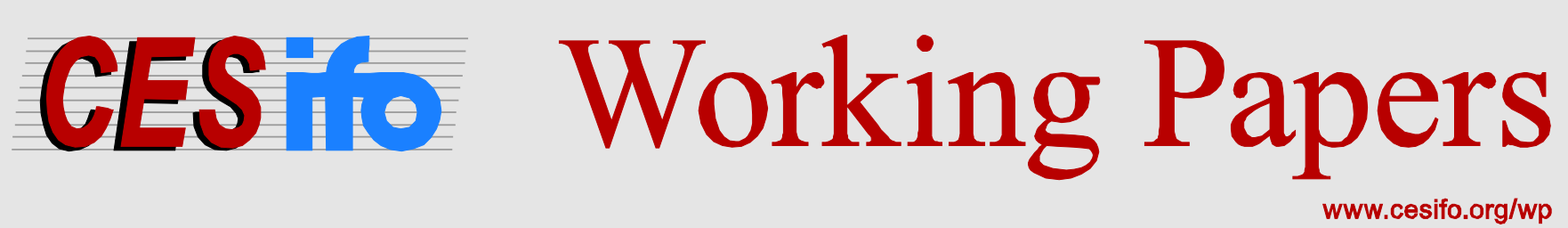

\title{
Climate Policy Enhances Efficiency: A Macroeconomic Portfolio Effect
}

\author{
Jan Siegmeier \\ Linus Mattauch \\ Ottmar Edenhofer
}

\begin{abstract}
CESIFO WORKING PAPER NO. 5161
CATEGORY 9: RESOURCE AND ENVIRONMENT ECONOMICS

JANUARY 2015
\end{abstract}

ISSN 2364-1428

An electronic version of the paper may be downloaded

- from the SSRN website: $\quad$ www.SSRN.com

- from the RePEc website: $\quad$ www.RePEc.org

- from the CESifo website: www.CESifo-group.org/wp 


\title{
Climate Policy Enhances Efficiency: A Macroeconomic Portfolio Effect
}

\begin{abstract}
Carbon pricing regulates emission flows and collects rents from underlying fossil resource stocks. The resulting investment shift implies lower climate policy costs and improved welfare if capital is underaccumulated. We prove that under emission trading, such a beneficial macroeconomic portfolio effect between fossil stocks and capital is induced if some permits are auctioned. Alternatively, a carbon tax also induces a portfolio effect, but cannot simultaneously implement a given mitigation path and collect an arbitrary rent share. Finally, treating the right to recurrently receive a share of total emission permits as a tradable asset is formally, but not politically equivalent.
\end{abstract}

JEL-Code: E220, H210, H230, Q300, Q540.

Keywords: carbon pricing, resource rent taxation, overlapping generations, capital underaccumulation.

\author{
Jan Siegmeier* \\ Mercator Research Institute \\ of Global Commons and Climate Change \\ Torgauer Str. 12-15 \\ Germany-10829 Berlin \\ siegmeier@mcc-berlin.net
}

Linus Mattauch

Mercator Research Institute of Global Commons and Climate Change

Torgauer Str. 12-15

Germany - 10829 Berlin

mattauch@mcc-berlin.net
Ottmar Edenhofer

Potsdam Institute for Climate Impact Research Postbox 601203

Germany - 14412 Potsdam ottmar.edenhofer@pik-potsdam

\footnotetext{
*corresponding author
}

December 16, 2014 


\section{Introduction}

A lack of political effort to implement ambitious climate change mitigation has frequently been justified by pointing out that other objectives, such as promoting economic growth, creating jobs or reducing inequality, take priority in national economic policy. Yet, most studies of the impacts of climate policy on growth and distribution have been conducted either on a sectorally resolved, technologically detailed level, analyzing effects on and between specific industries and households, or on an international level, considering the feasibility of agreements between nation states. However, the efficiency and the distributional effects of climate policy are neither confined to directly regulated sectors and technologies, nor to the international level: on a national scale, there are complex interactions with non-climate inefficiencies and policy goals, and appropriately designed climate policy instruments can improve overall efficiency and welfare ${ }^{1}$

Specifically, this paper shows that pricing the flow of carbon emissions, and thus appropriating rents from fossil resource stocks interpretable as 'climate rents', induces a macroeconomic distortion by directing investment towards producible capital as the alternative asset. If capital was previously underaccumulated, this 'macroeconomic portfolio effect' constitutes a welfare improvement and lowers the gross costs of climate policy.

This result has three major policy implications: First, and most importantly, there is generally an efficiency reason for the appropriation of climate rents for the public, rather than only a distributional motive - it may be necessary to collect the rents if the socially optimal allocation is to be implemented. Second, dynamic effects on stocks matter for the efficiency of flow-oriented climate policy instruments. Third, specifically for climate policy implemented as a permit scheme, the previous points imply an additional reason why permits should not be allocated for free.

Furthermore, the prominent role of rents from non-producible stocks in our analysis suggests an alternative climate policy instrument based on private property rights to the 'stock of the atmosphere': tradable rights to perpetually obtain a certain fraction of annual emission allowances. It has the same stock-flow structure and aggregate effects as conventional carbon pricing mechanisms, but different political economy implications.

We use a specific formal model and policy instrument, namely a two-asset overlapping-generations (OLG) model and three forms of carbon pricing, to prove the main result of this article. However, this specific model should be interpreted as an illustration of the more general idea of a beneficial macroeconomic portfolio effect due to rent collection via resource- and climate

\footnotetext{
${ }^{1}$ As a binding and sufficiently ambitious international agreement seems currently unlikely, independent national efforts come into focus - and with them, the effects of climate change and climate policy on national economies that may motivate such efforts (Edenhofer et al., 2014, Siegmeier et al., 2014).
} 
policy. This general idea is based on three major assumptions:

First, we assume that capital is suboptimally underaccumulated. This seems generally plausible if capital is broadly defined to include physical as well as human capital.

Second, the investment choice between capital and fossil resource stocks requires that both are available as privately owned, tradable assets in the economy under consideration. This may be the case either for a national economy that has both substantial fossil resources and capital goods, or for the world economy (interpreting rent collection as a global carbon pricing scheme). The liquidity of markets for emission-related assets also depends on the climate policy instrument chosen; for example, if the right to perpetually obtain a certain share of annual (national or global) emission rights was a tradable asset, the distribution of property rights to fossil resources would be less important for the portfolio effect to occur (see Section 4.3).

Third, we consider a situation where long-term climate policy has already been imposed - that is, the government has introduced an emission permit scheme, credibly committed to a path for the issuance of these permits and the degree to which they will be auctioned, and the economy has already adapted to each of these measures. We thus neglect the anticipation and transitional effects of the tax reform and only compare economic aggregates on balanced paths with limited emissions, but with or without rent collection 2

We relate our main result to four fields of research: We highlight its differences to literature on optimal climate policy and its international feasibility, and to literature on the existence of a "double dividend" of environmental taxation. We then point to its similarity to previous findings about rent taxation in public finance. Finally, important complementary results concern resource taxation under endogenous growth and asset price changes under avoided climate damages.

First, the bulk of literature on climate policy on the one hand uses relatively disaggregated models with high detail for emission-intensive sectors to identify optimal paths for greenhouse-gas (GHG) emission abatement and their costs (Clarke et al., 2014) and to compare different implementations of policy options in terms of efficiency and distribution (Fischer and Newell, 2008; Aldy et al. 2010; Asheim, 2012; Kalkuhl and Brecha, 2013). On the other hand, game-theoretical models with highly abstract nation states as players are used to analyze the political economy and thus feasibility of international climate policy (Finus, 2008, Stavins et al., 2014). Neither fo-

\footnotetext{
${ }^{2}$ This is relevant for cases such as the European Emissions Trading System (EU ETS), where permits were initially allocated for free, and auctioning was introduced gradually and without full prior anticipation. This option improves the political feasibility of introducing such a scheme, which may be an advantage over a carbon tax. See Koethenbuerger and Poutvaara (2009) and Heijdra et al. (2006) for a theoretical analysis of transition effects of introducing a tax on a fixed factor or pollution, respectively.
} 
cuses on the "intermediate" level of national economies and issues of public finance.

Second, the "double dividend" literature does address some of this gap: Given that an externality will be internalized by an environmental tax, using the revenues to cut pre-existing distortionary taxes is preferable to lumpsum redistribution by the very definition of a distortionary tax (Goulder, 1995). This constitutes a second dividend besides the environmental benefit. However, this positive revenue-recycling effect is counteracted by a "taxinteraction effect" (Bovenberg and De Mooij, 1994): the environmental tax increases the price of dirty goods, thus substituting a narrow-based implicit tax for a broad-based explicit tax, e.g. on labor. Thus, it is unlikely that the gross costs of an environmental tax swap are negative unless the initial tax system is inefficient (Goulder, 1995, Bovenberg, 1999). One potential source of inefficiency is inadequate taxation of rents from a fixed factor used in the production of a polluting good (Bento and Jacobsen, 2007): then, an environmental tax swap shifts some of the burden of taxation from labor to the fixed factor, and the price of the polluting good does not increase by the full amount of the environmental tax. Thus, the tax-interaction effect may be reduced and negative gross policy costs become more likely. While the effect presented here also stems from the collection of rents from a fixed factor, it is independent of a pre-existing distortionary tax system. Instead, increasing welfare in the economy is possible by addressing a dynamic inefficiency in savings behavior: Given that GHG emissions will be reduced, using a policy instrument that collects the rents from the emissions-related fixed factor (here, fossil resource stocks) to finance a given public revenue requirement is preferable to lump-sum taxation because it stimulates alternative, productive investments, i.e. capital accumulation. The effect is unambiguously welfare-enhancing if capital is otherwise underaccumulated. Moreover, it is independent of the recycling of the policy's revenues: In our specific model described below, we use climate policy revenues to finance public investment in resource efficiency improvements for analytical tractability, but in principle they could be used otherwise, e.g. for measures with a redistribution effect 3

Third, our contribution is related to results on non-environmental optimal taxation. The basic insight that a tax on rents from a fixed factor such as land generally is distortionary, since it directs investment away from land and towards capital, goes back to Feldstein (1977). Petrucci (2006) and Koethenbuerger and Poutvaara (2009) noted that this distortion is beneficial if capital was previously underaccumulated, e.g. due to imperfect intergenerational altruism. Edenhofer et al. (2013) provided a formal proof and

\footnotetext{
${ }^{3}$ Regarding redistribution, we formally show that the social optimum as defined by Calvo and Obstfeld (1988) can be reached if rent taxation is sufficient to finance both technical progress offsetting resource depletion and a redistribution scheme that addresses imperfect altruism between generations, the root cause of underaccumulation in our model.
} 
found that some forms of revenue recycling can establish the social optimum. Although Feldstein already suggested that his findings would apply to resource rent taxation, we are not aware of any work on this in the pertinent literature, nor related to environmental policy. Nevertheless, rents in the context of climate policy did recently receive some attention: Fullerton and Metcalf (2001) highlighted the creation of rents by different environmental policy instruments, and how their appropriation by the public sector affects the instruments' relative efficiency. Bauer et al. (2013) estimate the size of both the remaining resource rents and policy revenues (carbon rent) under climate policy regimes of different stringency; and Carbone et al. (2012) consider the potential of harnessing climate policy revenues for public debt reduction. However, the focus of these studies is on the size of and spending options for revenues of climate policy, while the macroeconomic effects of raising such revenues have been neglected. A potential reason for this is that collecting rents is still often presented as a non-distortionary source of public revenue (Stiglitz, 2014, Segal, 2011; Mankiw, 2008, Chapter 8), despite Feldstein's findings.

Finally, the contributions closest to the present paper are Groth and Schou (2007) and Karp and Rezai (2014b). The latter demonstrates, using a discrete OLG model, that climate policy can have aggregate beneficial effects due to a change in asset values. If capital is a fixed production factor, a Pareto-improving transfer is possible: If the mitigation necessitates some investments today, all generations welfare is increased except that of the current young. However, their effect is due to reducing overuse of a productive renewable resource and not to wealth effects due to the mitigation policy. (Karp and Rezai, 2014a) generalize the insight to the case of accumulable capital with adjustment costs for transforming consumption into investment goods and a climate damage function. Here we abstract from climate damages and focus on the wealth effects of the instruments that correct the externality. By contrast, Groth and Schou (2007) also consider taxation in general equilibrium with capital and non-renewable resources as alternative assets, but focus on its effects on long-run endogenous growth in a dynamically efficient setting with infinitely-lived agents. They show that taxation of a non-renewable resource that enters the "growth engine" of an economy affects long-run growth, while capital taxation does not.

The remainder of this article is structured as follows. Section 2 lays out the formal model, in which households own both capital and fossil resource stocks and are confronted with climate policy as a permit scheme. Section 3 presents the main result that such a climate policy induces a macro-economic portfolio effect: the higher the share of permits that is auctioned, the more investment is shifted away from fossil resource stocks and towards undersupplied capital, and the higher is social welfare. Section 4 discusses some of the model's assumptions and the effects of alternative policy instruments, such as a carbon tax. It also introduces a "stock instrument" related to per- 
sonal carbon trading schemes, and discusses its potential advantages over regulating the flow of emissions. Section 5 concludes.

\section{Model}

In this section, we set up a continuous overlapping generations (OLG) model (Yaari, 1965, Blanchard, 1985) to study whether climate policy induces a beneficial portfolio effect. There are two assets, capital and an exhaustible resource, no bequests (which leads to capital underaccumulation), and we assume technological progress in resource efficiency which is publicly financed. We keep brief our description of standard elements that have been developed in more detail elsewhere (Edenhofer et al., 2013). Climate policy is implemented here as a short-term, upstream emission trading scheme, i.e. permits have short lifetimes and regulate fossil resource extraction. This simplifies the exposition, since the path of resource extraction and emissions is exogenous. The next section analyzes the dependency of the balanced path on the share of permits that are auctioned to obtain the main result. The discussion section extends this result to policy instruments that keep resource extraction endogenous, such as a long-term permit scheme or a carbon tax.

On the supply side, assume a single final good produced from aggregate capital $K(t)$, labor $L(t)$ and fossil resource extractions $E(t)$ augmented by publicly provided technology $A(t)$. The production function has constant returns to scale, diminishing marginal productivity in individual inputs and satisfies the Inada conditions in all arguments. The representative firm's problem is

$$
\max _{K(t), L(t), E(t)} F(K(t), L(t), A(t) E(t))-[r(t)+\delta] K(t)-w(t) L(t)-b(t) E(t)
$$

yielding the standard first-order conditions

$$
r(t)+\delta=F_{K}(\cdot), \quad w(t)=F_{L}(\cdot), \quad b(t)=F_{E}(\cdot),
$$

where $\delta$ is the depreciation rate of private capital.

On the demand side, let $\phi$ be the birth rate, equal to each individual's instantaneous probability of death. Thus $\phi$ is also the death rate in the entire population (population size is constant and normalized to one) and individuals' lifetimes are exponentially distributed. If for individuals born at time $\nu$, some age-dependent variable at time $t$ has a value $x(\nu, t)$, its aggregate (population) value is denoted by the capital letter, and

$$
X(t)=\int_{-\infty}^{t} x(\nu, t) \phi e^{-\phi(t-\nu)} \mathrm{d} \nu
$$


At time $t$, an individual born at $\nu \leq t$ has expected lifetime utility

$$
u(\nu, t)=\int_{t}^{\infty} \ln c(\nu, \tau) e^{-(\phi+\rho)(\tau-t)} \mathrm{d} \tau
$$

with consumption $c(\nu, t)$ and rate of pure time preference $\rho$. Individuals' budget identity is

$$
\begin{aligned}
\dot{k}(\nu, t)+p(t) \dot{s}(\nu, t)+c(\nu, t) & =r(t) k(\nu, t)+[(1-T(t)) b(t)-p(t)] e(\nu, t)+ \\
& +w(t)-z(t)+\phi[k(\nu, t)+p(t) s(\nu, t)]
\end{aligned}
$$

with $\dot{k}(\nu, t)=\mathrm{d} k(\nu, t) / \mathrm{d} t$, etc ${ }^{4}$ Individuals own capital $k$, on which they earn interest at rate $r$, and a share $s$ of the total (exhaustible) fossil resource stock $S$, which they can sell or buy at a price $p$. Alternatively, they can extract an amount $e$ at zero cost and sell it at price $b$, but have to surrender a share $T$ of the revenue to the regulator. We assume that the resource stock is homogeneous and that all resource deposits are known (and fully owned), thus abstracting from new discoveries and (uncertain) technological change. Each individual receives the same wage $w$ and potentially pays a lumpsum tax $z$ (in Section 3.3, we discuss the consequences of age-dependent transfers $z(\nu, t)<0$ for social welfare). There are no bequest motives, but a competitive, no-cost life insurance sector to close the model, which pays an annuity $\phi(k+p s)$ in return for obtaining the individuals' assets in case of death. Thus, the changes in resource ownership of all living generations after accounting for extractions do not sum to zero:

$$
\int_{-\infty}^{t} \dot{s}(\nu, t) \phi e^{-\phi(t-\nu)} \mathrm{d} \nu+E(t)=\phi S(t)
$$

Finally, the individual also respects a solvency condition:

$$
\begin{array}{ll} 
& \lim _{\tau \rightarrow \infty}[k(\nu, \tau)+p(\tau) s(\nu, \tau)] e^{-R(t, \tau)}=0 \\
\text { with } & R(t, \tau) \equiv \int_{t}^{\tau}(r(\tilde{t})+\phi) \mathrm{d} \tilde{t} .
\end{array}
$$

The government implements an upstream climate policy that limits GHG emissions by limiting fossil resource extraction, and uses revenues from climate policy (and, for later comparison, lump-sum taxation) to finance technological progress offsetting the decreasing supply of fossil fuels. These policies do not result from endogenous maximization of a welfare criterion, but are exogenously given (see Section 4.1 for a discussion). More precisely, the government continuously limits aggregate resource extraction by issuing

\footnotetext{
${ }^{4}$ See Edenhofer et al. (2013) on the equivalence to a notation in terms of nonhuman assets $a=k+p s$. We separate the two assets here to make the portfolio effect more transparent.
} 
an exponentially decreasing amount of short-term extraction permit: $5 \bar{E}(t)$, so that

$$
E(t) \leq \bar{E}(t)=E_{0} e^{-\sigma t} .
$$

We assume that this constraint is binding at all times, i.e. that unregulated extraction rates would exceed the maximum permissible extraction rate $\sigma$. The total resource stock $S$ evolves according to

$$
\dot{S}(t)=-\bar{E}(t) .
$$

Using Equation (8) and setting $\lim _{t \rightarrow \infty} S(t)=0$ for simplicity (implying full extraction of the initial quantity $S_{0}$ ), we thus obtain $\bar{E}(t)=\sigma S(t)$ and $E_{0}=\sigma S_{0}$. A similar relationship holds for individuals, who do not choose $s$ and $e$ separately: even if there are several different resource stocks, their combination in individuals' portfolios is identical across homogeneous households. Thus individual resource owners will extract an amount $\bar{e}(\nu, t)$ in the same proportion to the aggregate admissible extraction as their individual resource share in the total resource stock, so $\bar{e}=\bar{E} s / S=\sigma s$. Suppressing time dependencies, we can then rewrite the budget constraint as

$$
\dot{k}+p \dot{s}+c=w+r k+[(1-T) b-p] \sigma s-z+\phi(k+p s) .
$$

The share $T$ of rents from resource extraction can be interpreted as an initial auctioning of a share $T$ of permits and free allocation of the remaining permits, or equivalently, as initial free allocation of all permits followed by a tax on revenues from resource extraction. Total revenues from this resource rent collection and lump-sum taxes $z$ are instantaneously invested into technological progress $I_{A}$. The government's budget identity thus is

$$
T(t) b(t) \bar{E}(t)+Z(t)=I_{A}(t) .
$$

Assume that the change in technological progress is linear in public investment into resource productivity improvements,

$$
\dot{A}(t)=\theta I_{A}(t) A(t),
$$

with $R \& D$ investment efficiency $\theta$. This assumption greatly simplifies the subsequent analysis, since the research investment required to exactly offset the regulated resource depletion at rate $\sigma$, which we denote by $I_{A}^{*}$, is then constant:

$$
I_{A}^{*}=\sigma / \theta
$$

\footnotetext{
${ }^{5}$ Extraction permits are equivalent to issuing permits for the amount of $\mathrm{CO}_{2}$ emissions that the use of the extracted resource will cause, but simplifies exposition here. Moreover, note that non-exponential mitigation paths can also be accommodated: the crucial assumption for reaching an analytical solution is that technological progress can keep effective resource supply constant. See Section 4.2 for a discussion.
} 
By Equation (12), this implies $A(t)=A_{0} e^{\sigma t}$, and thus by Equation (8), we have $A(t) \bar{E}(t)=$ const. $=A_{0} E_{0}$ : The "effective supply" of the fossil resource remains stable.

Individuals maximize utility (4) by choosing paths for $c$ and $s$, subject to budget identity (10) and solvency condition (7). From the first-order conditions of this optimization problem, one obtains the usual Keynes-Ramsey rule for the dynamics of individual consumption

$$
\frac{\dot{c}(\nu, t)}{c(\nu, t)}=r(t)-\rho
$$

and a no-arbitrage condition between the resource stock and capital (Appendix A.1):

$$
\frac{\dot{p}(t)}{p(t)}=r(t)+\frac{p(t)-[1-T(t)] b(t)}{p(t)} \sigma .
$$

The last term reflects the effect of exogenously imposing the resource extraction path.

From the instantaneous budget identity $(10)$, transversality condition (7) and no-arbitrage condition (15), we also obtain a lifetime budget constraint (Appendix A.2]:

$$
\begin{aligned}
\int_{t}^{\infty} c(\nu, \tau) e^{-R(t, \tau)} \mathrm{d} \tau & =k(\nu, t)+p(t) s(\nu, t)+h(\nu, t), \\
\text { with } h(\nu, t) & =\int_{t}^{\infty}[w(\tau)-z(\nu, \tau)] e^{-R(t, \tau)} \mathrm{d} \tau .
\end{aligned}
$$

Thus the present value of the consumption plan at time $t$ of individuals born at $\nu$ equals their total wealth of capital, fossil resources and the present values of lifetime labor income and (potentially age-dependent) taxes/transfers.

Solving the Keynes-Ramsey rule (14) for $c$ and substituting this in Equation (16) shows that each individual consumes the same fixed fraction of her total wealth (Appendix A.2):

$$
c(\nu, t)=(\rho+\phi)[k(\nu, t)+p(t) s(\nu, t)+h(\nu, t)] .
$$

We can now derive the remaining aggregate demand-side quantities according to (3) (see Appendix A.3). Using Equation (6), aggregation of Equation 17 yields

$$
C(t)=(\rho+\phi)[K(t)+p(t) S(t)+H(t)] .
$$

Aggregate consumption is the same constant fraction of total capital, resource, labor income and transfer wealth as for each individual. For the 
dynamics of the total capital stock, apply the definition of $K$, Leibniz' rule and the individual budget constraint 10 to get

$$
\dot{K}(t)=w(t)+r(t) K(t)+b(t) \bar{E}(t)-I_{A}-C(t) .
$$

The growth rate of aggregate consumption can be derived from the definition of $C$, using Leibniz' rule and Equations (14) and (17):

$$
\frac{\dot{C}(t)}{C(t)}=r(t)-\rho-\phi(\rho+\phi) \frac{K(t)+p(t) S(t)}{C(t)} .
$$

The last term is due to the "generation replacement effect": A share $\phi$ of the population, owning capital $K$ and resource wealth $p S$, dies and is "replaced" by newborns without assets. This continuous turnover of generations of different wealth also affects aggregate consumption growth, since consumption is a fixed fraction $(\rho+\phi)$ of wealth. The effect of newborns' lack of capital and fossil resources is always negative. Note that the dynamics of aggregate quantities are independent of "lump-sum" taxes $Z \sqrt{6}$

\section{Results}

In this section, we prove that climate policy may induce a beneficial portfolio effect (Theorem 1): The idea of the proof is to compare two ways of financing a given public revenue requirement (here, for $\mathrm{R} \& \mathrm{D}$ directed at resource efficiency improvements), either by a lump-sum tax or by auctioning some or all permits as a means to collect rents. Lump-sum taxation does not affect capital underaccumulation (which is a feature of the OLG model), while collecting scarcity rents from resource stocks makes investing in capital relatively more attractive, which enhances efficiency and welfare.

First, we characterize balanced paths on which capital and consumption stay constant while regulated resource depletion and R\&D offset each other (Section 3.1).

Then, we compare pure lump-sum R\&D funding to an auctioning of permits (or a tax on extraction revenues) on balanced paths. In the former case, there is underaccumulation, which is mitigated in the latter case, leading to higher aggregate consumption (Section 3.2).

The social optimum is defined as in Calvo and Obstfeld (1988), which implies that the Keynes-Ramsey levels of capital and consumption are socially optimal given the assumptions of our model (see Appendix A.4). It

\footnotetext{
${ }^{6}$ For age-dependent transfers $-z(\nu, t)$, there is a second "redistribution" effect: The aggregate population expects lifetime transfers of $-\bar{Z}(t)$, while newborns expect $-\bar{z}(t, t)$. The difference is an additional term in the numerator of the last fraction, the impact of which depends on how transfers redistribute wealth among generations. It only disappears for age-independent transfers, $\bar{Z}(t)=\bar{z}(t, t)$ (see also Section 3.3 Appendix A.3 and Edenhofer et al. (2013) for details).
} 
cannot be achieved, unless permit auctioning yields sufficient revenues in excess of technology investment which are redistributed to the benefit of the young rather than lump-sum (Section 3.3).

\subsection{Balanced paths}

The differential equations for the aggregate resource stock $S$, technology $A$, the resource stock price $p$, aggregate capital $K$ and aggregate consumption $C$ describe the dynamics of the economy (Equations (9), $(12),(15),(19)$ and (20), respectively). The price of the extracted resource $b$ and capital interest $r$ depend on $K, A$ and $S$ via the production function, so they do not add extra dimensions.

For simplicity, we will contrast below two polar cases of financing R\&D, either by permit auction revenues only, or purely by lump-sum taxation. For this reason, we assume that permit auction revenues are by themselves sufficient to finance the research investment level (13) chosen by the government to offset regulated resource depletion (8):

There exists a $T^{*} \in[0 ; 1]$ such that $I_{A}^{*} \leq T^{*} b(t) \bar{E}(t)$ for all $t$.

See 4.1 for further discussion of this assumption 7 . The inequality of course also implies that the alternative lump-sum financing of $R \& D$ is feasible in terms of potential revenues, too, since resource rents are part of each individual's lifetime income. If lump-sum taxes are politically infeasible, the consequence is a trade-off between the beneficial effect described below and distortions from other taxes, which is beyond the scope of the analysis presented here.

Then, with exogenously given depletion (8) and research (13) fixing the evolution of $S$ and $A$, balanced paths are described by

$$
\left\{K(t)=K^{*}, C(t)=C^{*}, S(t)=S_{0} e^{-\sigma t}, A(t)=A_{0} e^{\sigma t}, p(t)=p_{0}^{*} e^{\sigma t}\right\},
$$

where $A_{0}, S_{0}$ are given and $K^{*}, C^{*}, p_{0}^{*}$ denote the solution to the following

\footnotetext{
${ }^{7}$ Empirically, $I_{A}^{*}$ can be assumed to be significantly smaller than the mitigation costs of climate change, because these also comprise forgone consumption due to costly transformation of the capital stock (e.g. different power plants). However, the costs of climate change are very small compared to aggregate output or capital (in the order of 0.04 to 0.14 percentage points of reduction of annual consumption growth (IPCC, 2014)). Conceptually, our assumptions about the size of $I_{A}$ are distinctively un-Malthusian, because they insure that the transformation of the economy to a low-carbon state is possible at little cost and without disturbing stability .
} 
system of equations (using Equations (2))

$$
\begin{aligned}
& \dot{K}=0 \rightarrow \quad C_{P}(K)=F(K)-\delta K-I_{A}^{*}, \\
& \dot{C}=0 \rightarrow \quad C_{H}(K)=\phi(\rho+\phi) \frac{K+p_{0}(K) S_{0}}{r(K)-\rho}, \\
& \text { Eq.15 } \rightarrow \quad p_{0}(K)=\left(1-T^{*}\right) \sigma \frac{b_{0}(K)}{r(K)},
\end{aligned}
$$

written here with $K$ as the independent variable for convenience in the subsequent analysis. For the last equation, we substituted $\dot{p} / p=\sigma$ in the no-arbitrage condition, and used that

$$
b=F_{E}=F_{A E}(K, L, A E) A=F_{A E}\left(K, L, A_{0} E_{0}\right) A_{0} e^{\sigma t} \equiv b_{0}(K) e^{\sigma t} .
$$

The crucial policy parameter determining the values of $K^{*}, C^{*}$ and $p^{*}$ is the auctioned share of permits $T$, since the optimal choice of the extraction rate $\sigma$ or of the total amount of permits (represented here by the total available resource stock $S_{0}$ ) are assumed to be given.

Equation (22) defines a parabola-shaped curve in the $C$ - $K$-plane and Equation (23) a hyperbola. The $\dot{K}=0$ locus is shifted downwards relative to the origin by $I_{A}^{*}$. We assume that $I_{A}^{*}$ is sufficiently small so that two intersections of the parabola and hyperbola exist (for empirical plausibility see Footnote 7). While the lower is unstable, the upper is saddle-point stable. In the following, the system is reduced to two dimensions by maintaining $d(p S) / d t=0$. This projection captures all relevant dynamics ${ }^{8}$ We denote variables on the balanced path (where all three of Equations (22 24 hold) by an asterisk *. In particular,

$$
r^{*}=F_{K}\left(K^{*}\right)-\delta, \quad b_{0}^{*}=F_{E}\left(K^{*}\right) A_{0}, \quad p_{0}^{*}=(1-T) \sigma b_{0}^{*} / r^{*} .
$$

Finally, on the balanced path the growth factor $R(t, \tau)$ simplifies to

$$
R(t, \tau)=\int_{t}^{\tau}(r(\tilde{t})+\phi) \mathrm{d} \tilde{t}=\left(r^{*}+\phi\right)(\tau-t) .
$$

This simplification will be used for the rest of the article wherever balancedpath properties are discussed.

\footnotetext{
${ }^{8}$ This can be shown in the three-dimensional system: Linearizing around the steady states shows that the lower is unstable, while the upper is a saddle point with one stable arm. Since $C$ is a jump variable which instantaneously adjusts such that the optimality and transversality conditions are observed, the system is on the stable path, see Edenhofer et al. (2013) and appendices of Petrucci (2006). We merely subtract here a constant to one of the differential equations of the dynamical system examined previously. The above assumption about $I_{A}^{*}$ ensures that this does not change the topology of the phase space and thus also not its stability properties.
} 


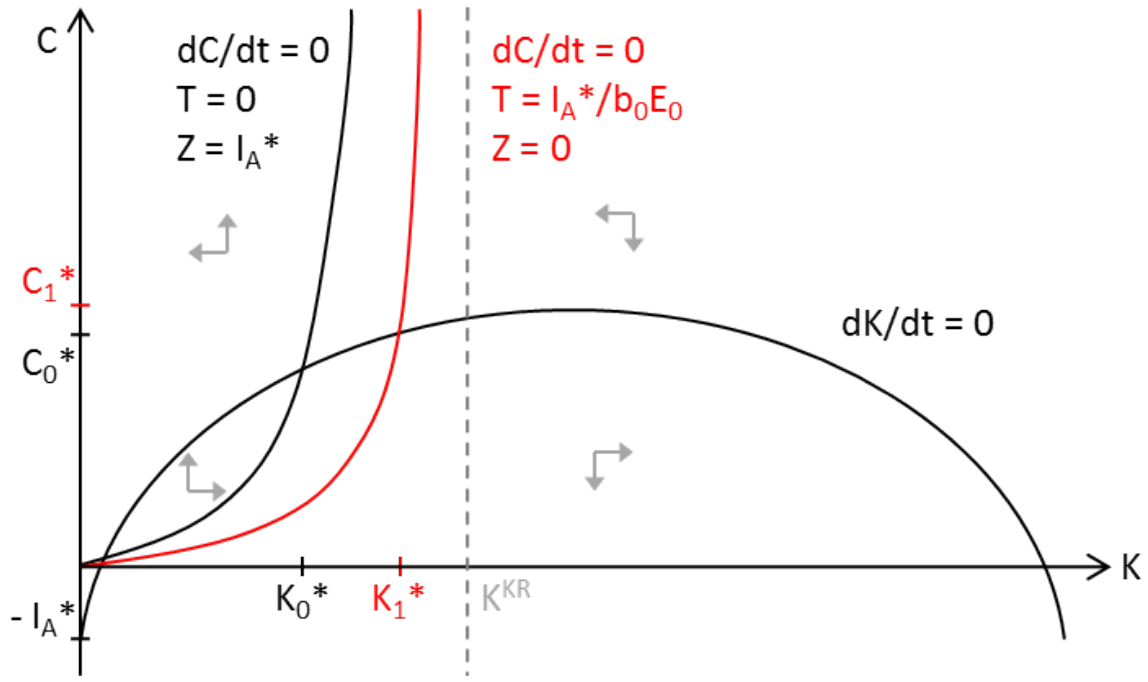

Figure 1: Phase diagram for aggregate consumption $C$ and capital $K . K^{k r}$ denotes the Keynes-Ramsey capital level, given by $F_{K}\left(K^{k r}\right)-\delta=\rho$.

\subsection{The macroeconomic portfolio effect of climate policy}

We now show that underaccumulation of capital due to the generation replacement effect can be mitigated by resource rent collection, which directs investment towards capital, but not by lump-sum taxation.

We first discuss why aggregate capital and consumption are suboptimally low. The reference point for social optimality are the Keynes-Ramsey steady-state levels of consumption $C^{k r}$ and capital $K^{k r}$, which satisfy

$$
\begin{aligned}
C^{k r} & =F\left(K^{k r}\right)-\delta K^{k r}-I_{A}^{*} \\
\text { and } \quad F_{K}\left(K^{k r}\right)-\delta & =\rho .
\end{aligned}
$$

This is derived using the approach of Calvo and Obstfeld (1988), see Appendix A.4.

Equation (23) is essential for analyzing the welfare effects of rent collection, since the position of the parabola (Equation 22) does not change. Solving for the steady state interest rate and using Equations (25) yields

$$
r^{*}=\rho+\phi(\rho+\phi) \frac{K^{*}+p_{0}^{*} S_{0}}{C^{*}}=\rho+\phi(\rho+\phi) \frac{K^{*}+(1-T) \sigma S_{0} b_{0}^{*} / r^{*}}{C^{*}} .
$$

Thus, the interest rate of the decentralized case is higher than the implied price of capital in the socially optimal steady state (Equation 27). From $F_{K K}<0$ and Equation (2) follows a lower level of capital, $K^{*}<K^{k r}$. Since $K^{k r}$ is left of the maximum of the parabola (22), a lower capital stock implies that consumption is suboptimal, $C\left(K^{*}\right)<C\left(K^{k r}\right)$. 
We now discuss the two policy cases, corresponding to the two hyperbolas in Figure 1. First, assume that there is no auction or tax on fossil resource extraction $(T=0)$ and that technological progress is financed by lump-sum taxation (the government's budget identity (11) becomes $Z^{*}=I_{A}^{*}$, which does not change the aggregate dynamics). Then, the second term in Equation (28) has its maximal value, and capital accumulation and aggregate consumption attain their lowest values (since the intersection of the hyperbola and the parabola is always to the left of the maximum of the parabola).

At the other extreme, with only the collected resource rents to finance technological progress $\left(\hat{T} b \bar{E}=I_{A}^{*}\right.$ and $\left.Z=0\right)$, underaccumulation is reduced relative to the lump-sum tax case, since the tax lowers $p_{0} S_{0}$, so ceteris paribus the second term in Equation $(28)$ is smaller. The intuition is that the lower rent earnings make investing in the resource stock less attractive than capital investment, as reflected in the no-arbitrage condition (15), and thus causes a rebalancing of the asset portfolio. Also, a lower resource stock price means less "missing wealth" for the newborns, and thus a smaller generation replacement effect (but the effect is still non-zero for all $T$, so the social optimum cannot be reached without additional policies, see next subsection). These effects are of course not isolated, but interact via general equilibrium effects. We thus formalize and prove the effect, also allowing for combinations of both financing options.

Theorem 1. Suppose that the economy is on a balanced path on which publicly financed technological progress exactly offsets decreasing availability of short-term (extraction) permits, that any share of these permits may be auctioned or allocated for free, and that lump-sum payments are available. Then, the higher the share of permits that is auctioned, the higher is social welfare.

This result is proved in Appendix A.5 by showing that the higher the auctioned share of permits $T$, the higher are aggregate capital and consumption. The basic message is that it is welfare-enhancing to fulfill the revenue requirement for $R \& D$ investment by distortionary auctioning of permits instead of fulfilling it by non-distortionary lump-sum taxation (which should only close a potential gap if revenues from full auctioning are insufficient). However, the theorem is stronger: It implies that even if the revenue requirement can be fulfilled without auctioning all permits, it is still desirable to auction permits to the largest degree possible for efficiency reasons. Revenues in excess of $R \& D$ investment needs are redistributed here by a lumpsum transfer that is uniform across all generations; other transfer schemes are explored in the next subsection.

As a direct consequence of Theorem 1, the gross costs of climate policy are reduced if permits are auctioned because the costs of introducing a climate policy regime relative to scenarios in which there is no mitigation (not modeled here) is reduced by the efficiency gain described in our model. 


\subsection{Non-uniform revenue redistribution and social optimal- ity}

As an extension to the basic model above, we now show that if climate policy revenues exceed $R \& D$ financing requirements, they can be used for age-dependent transfers that may establish the social optimum.

If resource revenues exceed required $R \& D$ investments $\left(T^{*}<1\right)$, it can be seen from Equations (23), (24) and (28) that raising the auctioned share above $T^{*}$ further reduces the value of the fossil resource and the interest rate, and increases the capital stock and consumption. But due to the missing capital wealth $\phi K$ of the newborns, the generation replacement effect never fully disappears by this price effect alone (the second term in Equation 28) remains positive). It only disappears if the revenues in excess of required R\&D investments are used for age-dependent transfers to the newborns. This is proved by Edenhofer et al. (2013), whose results apply directly to our case as well, only accounting for the need to finance $R \& D$ along with transfers:

If lump-sum payments $z$ that enter individuals' budget constraint (5) are potentially age-dependent $(z=z(\nu, t)$, instead of $z(t))$, we obtain a more general expression for aggregate consumption growth (while all other equations for aggregate dynamics remain unchanged; see Appendix A.3.

$$
\frac{\dot{C}(t)}{C(t)}=r(t)-\rho-\phi(\rho+\phi) \frac{K(t)+p(t) S(t)-\bar{Z}(t)+\bar{z}(t, t)}{C(t)} .
$$

Thus, for rent collection financing age-dependent transfers (negative $z$, which were defined as taxes), there is a "redistribution effect" additional to the price effect discussed above: The difference between the expected transfers to the aggregate population $\bar{Z}(t)$ and to newborns $\bar{z}(t, t)$ reflects how transfers redistribute wealth among generations, and thus affects the size of the generation replacement effect. Only if transfers are age-independent $(\bar{Z}(t)=\bar{z}(t, t))$, the difference is zero and the redistribution affect disappears 9 If, on the contrary, transfers are biased towards newborns, the social optimum may be established. For the case where only newborns receive any transfers, we have

$$
\begin{aligned}
\bar{z}_{n}(t, t) & =-\frac{T b(t) \bar{E}(t)-I_{A}(t)}{\phi}, \\
\bar{z}_{n}(\nu, t) & =0 \text { for } \nu>t \quad \text { and } \\
\bar{Z}_{n}(t) & =0 .
\end{aligned}
$$

\footnotetext{
${ }^{9}$ Thus, the expressions 20 above and $\dot{H}=(r+\phi) H-w+Z$ (with $Z$ defined as a tax), often considered standard results in the literature (Petrucci, 2006, Marini and van der Ploeg, 1988), are in fact a special case.
} 
The auctioning (or extraction tax) rate that reproduces the social optimum on the balanced path, for which the generation replacement effect disappears, is

$$
T^{o p t}=\frac{\phi\left(K^{*}+p_{0} S_{0}\right)+I_{A}^{*}}{b_{0} \sigma S_{0}}=\frac{\phi\left(r^{*} K^{*}+b_{0} \sigma S_{0}\right)+r^{*} I_{A}^{*}}{\left(r^{*}+\phi\right) b_{0} \sigma S_{0}} .
$$

For age-independent transfers, underaccumulation is mitigated by the price effect, but cannot be fully cured even for $T=1$. For transfers to newborns only, the additional redistribution effect can compensate newborns' "missing capital" and establish the social optimum. Both effects together may even lead to overaccumulation, so the optimal auctioning share may be smaller than one. See Edenhofer et al. (2013) for further details and other redistribution schemes.

\section{Extensions: further policy instruments}

The main result of the present article builds on the assumption that climate policy consists of an emission trading scheme with permits with a short lifetime. This section explores alternative climate policy instruments: emission trading with long permit lifetime, a carbon tax and a hitherto unexamined instrument that limits availability of the atmospheric stock directly rather than the annual flow of emissions. Comparing these instruments to the case of short-term permits highlights the robustness of our result and further develops the intuition of our argument.

The first subsection discusses the sensitivity of the portfolio effect on the main modeling choices concerning resource availability. We conclude that the essential assumption for our analysis above is the short lifetime of the permits, which fixes the extraction (emission) path exogenously.

Consequently, the second subsection discusses alternative instruments for which extraction is endogenous. A long-term permit scheme and a constant carbon tax can be shown (for a Cobb-Douglas production function) to induce the same macroeconomic portfolio effect as a short-term permit scheme; for a time-dependent carbon tax, this seems probable but formally remains a conjecture. Additionally, while total emissions and rent collection can be chosen separately for permit schemes, there is a trade-off under a carbon tax: a high constant tax maximizes the portfolio effect, but a time-varying tax is needed for effective emission reduction.

The third subsection describes the "stock instrument": households hold tradable ownership certificates to the stock of the atmosphere rather than permits to a flow of emissions. This instrument is equivalent to a conventional permit scheme under the assumptions employed here. However it may be more effective in more realistic settings in which fossil resources are not perfectly tradable and households are motivated to protect the environment. 


\subsection{Premises of the short-term permit scheme model}

The above model of an emission trading scheme has been easily tractable (despite the OLG structure) for two reasons: Short permit lifetimes allow for a direct control of the extraction path. Additionally, we exploited the fact that the degree of rent extraction can be chosen independently from the extraction path: by requiring that the revenues equal the investments into resource productivity improvements that are necessary to exactly offset declining resource supply, a balanced path is established.

We now discuss the restrictiveness of the underlying assumptions:

First, we chose a specific shape of the permissible extraction path, and resource efficiency improvements: for simplicity, we chose an exponentially declining extraction path $\left(E(t)=E_{0} e^{-\sigma t}\right)$, and accordingly assumed that R\&D investment translate into resource efficiency improvements as $\dot{A}=\theta I_{A} A$, so that $I_{A}=\sigma / \theta$ leads to $A(t) E(t)=$ const. An exponential extraction path is analytically convenient, but the exact shape of the path is irrelevant for our results as long as technological progress is such that spending no more than a certain fraction of output on $R \& D$ can offset the decreasing resource supply. This optimistic assumption about technology is a mere artifice to obtain an analytical solution.

Second, we require public financing of resource efficiency improvements: An alternative would be to assume exogenous technological progress. We use publicly-financed $R \& D$ to underline (1) the necessity of $R \& D$ to counter mitigation-induced scarcity, and (2) that even if the mitigation path is given, the government still has a choice regarding $R \& D$ investment. The government's optimization problem that should determine this choice is not modeled here. Completely offsetting resource scarcity and maintaining a steady state via R\&D is chosen merely for simplicity. Furthermore, public investment in resource efficiency improvements could be interpreted to also include investment in infrastructure that matches resource-efficient technologies, such as railways, public transport and bike lanes, charging infrastructure for electric vehicles, or electricity grids and system services necessary for integration of fluctuating renewable sources of energy.

Third, related to the second point, we assume that public financing of $\mathrm{R} \& \mathrm{D}$ is feasible - technologically, as ensured by assumptions on the production function, and in terms of available fiscal instruments, since if climate policy revenues are insufficient, lump-sum taxes are available in our model to top them up.

Fourth, we assume "short" lifetimes of permits to fix the extraction path: due to inertia of the climate system, what matters are the cumulative GHG emissions over longer periods (several decades), not their short-term path (Meinshausen et al., 2009, Ciais et al., 2013). However, practical implementations of climate policy via emission trading schemes, such as the EU ETS and the California Cap-and-Trade scheme, operate on shorter time scales, 
with emission budgeted over trading periods of eight and three years, respectively. Forward 'banking' of unused permits is generally allowed, but can be neglected if we assume that emission budgets are a binding constraint. More importantly, 'borrowing' of permits to delay mitigation is not possible in California, and restricted to within a trading period in the EU, so the endogeneous exhaustion of the short-term budget can be approximated well by a fixed path. The fixing of such a long-term mitigation path by the government is not necessarily less efficient than a decentralized solution, depending e.g. on whether individual agents or the government are more forward-looking.

This supports our modeling of a short-term permit scheme above. Yet it remains to be shown if our hypothesis also holds for other policy instruments, to which we turn next.

\subsection{Carbon tax and long-term permit scheme}

The main difference of a carbon tax compared to a short-term permit scheme is that the last of the assumptions above is relaxed, i.e. the extraction path is determined endogenously, and it may be affected by the path of the tax. Extraction is also endogenous under permit schemes with unrestricted banking and borrowing between periods or long permit lifetime (once the permits are auctioned). In this sense, they resemble a carbon tax rather than a short-term permit scheme, so the conclusions drawn in the following for a carbon tax similarly apply.

We start by modifying the resource extraction part of our continuous OLG model for a carbon tax instead of a short-term permit scheme. We then show that a government aiming to establish a balanced path with constant aggregate capital and consumption not only needs to invest into technological progress to offset resource scarcity as before, but also has to keep the carbon tax constant. In such a setting, the full dynamical system resembles the short-term permit case, so Theorem 1 can be extended: a higher constant carbon tax level (higher constant permit auctioning rate) leads to higher social welfare. Thus, there is some climate change mitigation even under a constant carbon tax: Although it does not directly affect the path of resource extraction and GHG emissions (Dasgupta and Heal, 1979), the portfolio effect leads to a higher capital stock and lower interest rate, so extraction is slower. This also holds for a long-term permit scheme with constant auctioning - but here, the total amount of emissions can additionally be limited to any desired level by capping the total amount of available resources on its introduction: In the case of the carbon tax, $S$ stands for the fossil reserves, in the case of a permit scheme it is the remaining carbon budget. Finally, we briefly consider scenarios where the system is not on a balanced path, because effective climate policy is imposed by a non-constant carbon tax (which implies different growth rates of the resource stock and 
the resource stock price, so that the OLG-specific generation replacement effect is non-constant). Even then, a macroeconomic portfolio effect can be conjectured to occur; but the carbon tax remains less flexible than a short-term permit scheme, independent of assumptions about technological progress, since choosing a mitigation path fixes the path of revenues from rent collection.

Assume an OLG model with two assets, capital and an exhaustible resource, as above, but endogenous extraction under a (potentially timedependent) carbon tax instead of an exogenously given extraction path implemented by a short-term permit scheme. The carbon tax is interpreted as an ad-valorem tax on resource extraction and may be used to finance resource efficiency improvements.

The firms' problem remains unchanged. On the demand side, with individual resource extraction $e$ as an independent control variable, the individual budget identity (5) does not simplify to (10), and the path of aggregate resource stock is endogenous (we suppress time dependencies in the following):

$$
\dot{S}=-E .
$$

Individual optimization yields a simpler no-arbitrage condition than before, identical to the well-known Hotelling rule, and an additional condition on resource prices:

$$
\begin{aligned}
\dot{p} / p & =r, & & 15 a) \\
p & =(1-T) b . & & 15 b)
\end{aligned}
$$

Thus, while resource extraction $e$ and resource stock ownership $s$ can be chosen separately, their prices are not independent. However, they may grow at different rates: Combining the two conditions gives

$$
\dot{b} / b=r+\psi \quad \text { with } \quad \psi:=\dot{T} /(1-T),
$$

so a decreasing tax $(\psi<0)$ implies that $p$ grows faster than $b$. From the firms' first-order conditions (2), we have

$$
\frac{\dot{b}}{b}=\frac{\dot{F}_{E}(K, L, A, E)}{F_{E}(K, L, A, E)}=\frac{\dot{A}}{A}+\frac{\dot{K} F_{E K}}{F_{E}}+\frac{(\dot{A} E+A \dot{E}) F_{E E}}{A F_{E}} .
$$

Substituting this into $(15)$ and solving for $\dot{E}$ shows that ceteris paribus (in particular for constant $K$ ), the resource extraction rate depends on the change rate of the tax, but not on its level.

The dynamics of aggregate capital and aggregate consumption remain unchanged:

$$
\begin{aligned}
& \dot{K}=w+r K+b E-I_{A}-C, \\
& \frac{\dot{C}}{C}=r-\rho-\phi(\rho+\phi) \frac{K+p S}{C} .
\end{aligned}
$$


For the government, we have

$$
\begin{aligned}
T b E+Z & =I_{A}, \\
\dot{A} & =\theta I_{A} A .
\end{aligned}
$$

Compared to the short-term permit case, government-controlled extraction $\bar{E}(t)$ has been replaced by $E(t)$, which is determined endogenously from the households' problem above. The government takes into account the firms' and households' first-order conditions (thus being the leader in a Stackelberg game) when it chooses the carbon tax $T$ and public investment in resource efficiency improvements $I_{A}$. These are balanced in the government's budget by lump-sum taxes or transfers $Z$, if necessary.

Assume that the government seeks to establish a balanced path with $K(t)=K^{*}, C(t)=C^{*}$. From Equation 190 follows that this requires the marginal resource productivity to grow as fast as resource supply declines (otherwise output is not constant), while for the generation-replacement effect in Equation (20) to stay constant, the resource stock price has to grow as fast the resource stock declines, so we have

$$
\begin{aligned}
\frac{d}{d t}(A E) & =0, \\
\frac{d}{d t}(p S) & =0 .
\end{aligned}
$$

Appendix A.6 shows that these conditions can be satisfied on a balanced path by choosing

$$
\begin{aligned}
I_{A} & =1 / \theta(-\dot{E} / E), \\
\psi & =0,
\end{aligned}
$$

so a balanced path only exists under a carbon tax if the tax is constant. On such a balanced path, we have

$$
\dot{b} / b=\dot{p} / p=\dot{A} / A=-\dot{E} / E=-\dot{S} / S=r\left(K^{*}\right),
$$

since as long as the carbon tax and $R \& D$ investment are constant, the resource stock and resource extraction change at the same rate, so the price for the extracted resource and the stock also need to evolve at the same rate. A non-constant carbon tax would drive a wedge between them $(\dot{p} / p=r=$ $\dot{b} / b-\psi)$.

Nevertheless, a balanced path is consistent with a constant carbon tax of any level (except $T=1$, for which the resource stock market would collapse). On such a path, the contribution of resource wealth to the generation replacement effect is constant, but smaller for a higher carbon tax $\left(p S=(1-T) b_{0}\left(K^{*}\right) S_{0}\right)$. Thus, the following result holds (proved in Appendix A.6): 
Corollary 2. Assume that production can be described by a Cobb-Douglas function. Suppose the decreasing availability of fossil resources is exactly offset by technological progress, which is publicly financed by the revenues of a constant carbon tax and, if necessary, lump-sum taxes. Then, the higher the absolute level of the constant carbon tax, the higher is social welfare.

As indicated above, this result is similarly applicable to the case of an emission trading scheme with long permit lifetimes or unlimited banking and borrowing between periods: On a balanced path, a long-term permit scheme that leaves the determination of the extraction path to the market, but collects fossil resource rents by perpetually auctioning (a share of) permits and financing resource efficiency improvements, does also induce a macroeconomic portfolio effect. Again, higher auctioning rates unambiguously imply higher consumption and thus higher welfare. However, unlike a constant carbon tax, it can additionally implement the most important aspect of climate policy by directly restricting cumulative emissions to any desired extent (by interpreting $S_{0}$ as a carbon budget and setting it to a fraction of fossil resource reserves). A constant carbon tax only changes the extraction path indirectly via the portfolio effect, because a higher capital stock and lower interest rate leads to slower extraction.

Finally, consider a non-constant carbon tax that affects the endogenous extraction path (Dasgupta and Heal, 1979). The tax will need to decrease to provide an incentive for resource conservation and thus mitigation (Sinclair, 1994). As we saw above, this does not result in a balanced path in a continuous OLG setting (so we cannot apply the same analytical method as above). Nevertheless, some part of the fossil resource rent still is extracted by the carbon tax, the value of the fossil stock is reduced and saving in producible capital becomes more attractive, so the basic effect can be expected to hold for a non-constant carbon tax as well:

Conjecture 3. The macroeconomic portfolio effect still holds under a timedependent carbon tax.

Even a time-dependent carbon tax is still less flexible than a permit scheme: If the extraction path is fixed by the carbon tax, the path of tax revenues is also fixed - in contrast to a short-term permit scheme, in which the amounts available for extraction can be chosen independently from the auctioning rates (which may be constant, as above, or vary over time). Without this additional flexibility, it is not possible to implement a given mitigation path and arbitrary rent collection simultaneously. Instead, there is a tradeoff: the macroeconomic portfolio effect induced by a time-dependent carbon tax is weaker than under a permit scheme to the extent that the mitigation incentive of a falling tax rate is given priority. 


\subsection{Owning the atmosphere: A "stock instrument"}

The stock-flow structure of our model also suggests an alternative instrument: Instead of regulating the flow of emissions, one could limit the availability of the stock and make claims on it tradable: Households obtain property rights for the atmosphere and the government regulates to how much annual emissions this entitles them. We first describe what the instrument consists in and subsequently show that it is equivalent to the model presented earlier in this article. We then consider two arguments why the stock instrument may be preferable to a short-term permit scheme: fossil resources may be less tradable than atmospheric property rights, and a stock instrument may lead to enhanced environmental awareness compared to conventional emission trading.

We suggest a stock instrument for climate policy with the following structure: Assume that households own shares $s_{a}$ of the atmosphere (instead of shares of fossil resource stocks). Ownership of such shares entitles them to annually obtain emission rights, the amount of which decreases at rate $\sigma$. Households can sell these emission rights to firms at a price $l$ and pay taxes on the revenues (they "rent out" their share of the atmosphere to the firms). They can also trade the shares among each other. Our suggestion is related to the "long-term permit" component of the McKibbin-Wilcoxen hybrid climate policy (McKibbin and Wilcoxen, 2002), which those authors also allow to embody declining annual emission rights (McKibbin and Wilcoxen, 2007; McKibbin, 2012) ${ }^{10}$ However, this type of permit system has not been considered in an analytical model before the present article. It is also related to the case of "exogenously shrinking" land considered by Buiter (1989) in the context of debt neutrality of taxation of fixed factors.

For this alternative instrument, the model presented in Section 2 is modified as follows: The individual budget becomes

$$
\dot{k}+p \dot{s}_{a}+c=w+r k+[(1-T) l-p \sigma] s_{a}-z+\phi\left(k+p s_{a}\right) .
$$

Here the contribution $-p \sigma s_{a}$ comes from the annual decrease in emission rights attached to the ownership of an atmospheric stock. The dynamics of the atmospheric stock are controlled by the government and, as above, taken to be

$$
\frac{\dot{S}_{a}}{S_{a}}=-\sigma
$$

Its decreasing availability reflects the limited disposal space for emissions. Still $\dot{S}_{a}=-E$, so that $E=\sigma S_{a}$. So $\sigma$ is both the rate of decline of the

\footnotetext{
${ }^{10}$ The nature of the "long-term permits" is not central to the major advantages of the hybrid climate policy propounded by (McKibbin and Wilcoxen, 2002). In (McKibbin and Wilcoxen 2007), the authors attribute the suggestion of embodying declining emission rights into a long-term permit to Rob Stavins, while in (McKibbin, 2012) some advantages to this specific design are briefly mentioned, see also below.
} 
atmospheric stock as well as the ratio between emissions used and total available space in the atmosphere. In particular, while households rent out their share of the atmosphere to the firm for one year, $E$ denotes the emissions permitted in production, which are proportional to the current given size of $S_{a}$. Hence

$$
l=F_{S_{a}}\left(K, L, A E\left(S_{a}\right)\right)=F_{E}\left(K, L, A E\left(S_{a}\right)\right) \sigma .
$$

The remaining modification to the previous model is Equation (6), which has to be changed to

$$
\int_{-\infty}^{t} \dot{s}(\nu, t) \phi e^{-\phi(t-\nu)} \mathrm{d} \nu-\sigma S(t)=\phi S(t),
$$

as the atmospheric stock shrinks without being used. The remaining defining equations of the model are identical. The only change to the dynamics of the model is a no-arbitrage condition between the atmospheric stock and capital:

$$
\frac{(1-T) l}{p}+\frac{\dot{p}}{p}=r+\sigma .
$$

As the remaining equations describing the dynamics of the economy are unchanged, the stock instrument will be equivalent to the short-term permit scheme, if $l=b \sigma$. This holds by Equation (39). The equation between prices $l$ and $b$ is true because renting the stock of the atmosphere $S_{a}$ at rate $l$, or buying a flow of resources $\bar{E}=\sigma S$ at price $b$, must have the same value to firms. Thus, the original and modified budget equations are the same. The deeper reason for this equivalence is that the short-term permit scheme already contains the core of the stock instrument, which is to treat $e$ as proportional to $s$ and thus to prevent endogenous extraction dynamics.

While the stock- and flow instruments are formally equivalent in our model of a closed, competitive economy, where everyone owns resources (or parts of the atmosphere), differences may arise in more realistic settings. The two instruments seem to imply different distributions: While considering the fossil resource stocks underlying an emission trading scheme evokes that "only resource owners" possess such assets, introducing a new property structure is associated with the idea that "everyone gets permits". However, an initial or perpetual reallocation of shares of the stock is in principle possible for both instruments, so differences between the two instruments do not arise primarily from different distributions. Instead, we discuss two genuine distinctions:

First, the models of this article rest on the assumption that the fossil resource or atmospheric stocks are fully tradable. Yet in economic reality, there may be several classes of agents, or heterogeneous countries which mostly hold either capital assets or fossil resources. If there are investors that specialize on one class of assets only, or are barred from investing in the 
alternative class of assets, a portfolio effect may not occur, as fossil resources are not fully traded. A stock instrument, in contrast, creates assets that are (designed to be) fully tradable, overcoming a possible "separation" of assets that could weaken the portfolio effect if climate policy was introduced as a conventional short-term permit scheme.

Second, a standard argument against implementing climate policy by an emission trading system is that it crowds out social preferences, namely personal motivation to behave in an environmentally-friendly way (Frey, 1999 Bowles and Polania-Reyes, 2012). An alternative climate policy could attempt to make the scarcity of carbon sinks more tangible to individuals, and provide them with an opportunity to express social preferences directly and visibly for others. A consequence of such a policy may be greater political support for introducing or tightening a cap on emissions (see also McKibbin, 2012). This has been the chief motivation behind the idea of personal carbon trading (PCT) schemes (Hillman, 1998, Fleming, 1997) to which our suggestion of a "stock instrument" is related. They have been discussed in some theoretical detail (Starkey, 2012a b) and also received considerable interest from policy makers (Fawcett, 2010). The schemes closest to our model are the Ayres scheme (Ayres, 1997) and the Cap\&Share scheme (as described in Starkey, 2012a), where every year, a decreasing amount of tradable emission rights is initially allocated to individuals on an equal per capita basis, and can then be sold on to emitting firms. In addition to this flow market, our suggested instrument involves a "secondary" stock market where rights to the flow of individuals' future allocations of permits are traded as an asset. Thus, while PCT only differs from conventional emission trading systems by regulating emissions directly at the level of the households, our proposed stock instrument would additionally give households some "property rights" to the atmosphere, with ensuing investment decisions. Whether such a policy may enhance environmental awareness and may be more socially acceptable than conventional emissions trading is a question for future research.

\section{Conclusion}

In his seminal contribution on rent taxation Feldstein (1977, p.356) wrote that "[i]ncreasing the effective rate of tax on natural resources creates a capital loss for the current owners and thus induces additional capital accumulation". For the case of climate policy, this effect has so far been unexamined. The present article therefore has studied the impact of climate policy on aggregate investment behavior. For an emission trading system in which permits have short life times, auctioning of permits was proved to induce a shift of investment away from fossil resource stocks towards producible capital. If capital is underaccumulated - a plausible assumption if capi- 
tal is broadly conceived and includes human capital - this "macroeconomic portfolio effect" increases efficiency and thus social welfare. The effect also implies that the gross costs of climate policy are lower compared to cases in which rent extraction is allocation-neutral. If imperfect intergenerational altruism is the source of capital underaccumulation, using the revenues from rent-extracting policies to the benefit of the young may even establish the social optimum.

A similar effect occurs for the case of a carbon tax (or a permit scheme with long permit lifetimes), which is however not equivalent to a shortterm permit scheme: the tax rate (or auctioning share) is the only policy variable and the resource extraction path is endogenous, while under a shortterm permit scheme the share of permits to be auctioned and the resource extraction path can be chosen separately.

The portfolio effect relies on the assumption that the resource stocks affected by the conventional, "flow-based", permit scheme are tradable assets directly competing with capital goods. If this is not the case, and in particular in settings with several countries or classes of agents with different resource endowments, a "stock-based" scheme that introduces ownership of a share of perpetually renewed emission rights may offer a remedy: while being formally equivalent to the conventional permit scheme, the new asset may be more liquid and more widely available. Furthermore, environmental awareness and political feasibility of stringent climate policy could be enhanced by distributing atmospheric property rights instead of implementing an upstream emissions trading system.

We conclude that extracting resource rents (e.g. by climate policy) is efficient due to dynamic investment effects, and not only desirable for distributional reasons. Furthermore, if climate policy is implemented as a permit scheme, investment dynamics provide a new reason for the old conclusion that permits should not be allocated for free.

\section{Acknowledgements}

We thank Anselm Schultes for insightful discussions. Financial support from the Michael-Otto-Stiftung for the Chair Economics of Climate Change at TU Berlin is gratefully acknowledged. Linus Mattauch thanks the German National Academic Foundation for financial support through a doctoral scholarship. 


\section{A Appendix}

\section{A.1 Derivation of the Keynes-Ramsey rule and the arbitrage condition}

The budget constraint (10) can be split into a constraint in monetary terms and another in terms of the fossil resource by defining $d(\nu, t)=\phi s(\nu, t)-$ $\dot{s}(\nu, t)-\bar{e}$, where $\bar{e}=\bar{E} / S s=\sigma s$. Dropping the time arguments, we obtain:

$$
\begin{aligned}
\dot{k} & =w+[r+\phi] k+(1-T) \sigma b s+p d-z-c \\
\dot{s} & =\phi s-d-\sigma s .
\end{aligned}
$$

Individuals maximise utility given by Equation (4) by choosing $c(\nu, t)$ and $d(\nu, t)$, subject to Equations (40), (41) and the transversality condition (7). Writing $\lambda$ and $\mu$ for the multipliers of (40) and (41) in the current value Hamiltonian $H_{c}$, we obtain the following first order conditions:

$$
\begin{aligned}
& \frac{\partial H_{c}}{\partial c}=\frac{1}{c}-\lambda=0 \\
& \frac{\partial H_{c}}{\partial d}=\lambda p-\mu=0 \\
& \frac{\partial H_{c}}{\partial k}=(\rho+\phi) \lambda-\dot{\lambda} \quad \Rightarrow \quad \lambda(r+\phi)=(\rho+\phi) \lambda-\dot{\lambda} \\
& \frac{\partial H_{c}}{\partial s}=(\rho+\phi) \mu-\dot{\mu} \quad \Rightarrow \quad \lambda(1-T) \sigma b+\mu(\phi-\sigma)=(\rho+\phi) \mu-\dot{\mu} .
\end{aligned}
$$

Inserting the time derivative of (42) into Equation (44) yields the KeynesRamsey rule (14). Using Equation (43) and its time derivative to replace $\mu$ and $\dot{\mu}$ in Equation (45) and applying Equation (44) gives the arbitrage condition for investing in fossil resources or capital (15).

\section{A.2 Individual lifetime budget constraint and consumption level}

First, to derive the lifetime budget constraint (16), regrouping terms in 10 ) and adding $\dot{p} s-(r+\phi) p s$ on both sides gives:

$$
\begin{aligned}
\dot{k}+p \dot{s}+\dot{p} s-(r+\phi)(k+p s) & =w+(1-T) \sigma b s-p \sigma s+\dot{p} s-r p s-z-c= \\
& =w-z-c .
\end{aligned}
$$

The last equality follows from (15). This leads to

$$
\begin{aligned}
\frac{d}{d \tau}\left[(k+p s) e^{-R}\right] & =(w-z-c) e^{-R} \\
\Rightarrow \int_{t}^{\infty} \frac{d}{d \tau}\left[(k+p s) e^{-R}\right] \mathrm{d} \tau & =\int_{t}^{\infty}(w-z-c) e^{-R} \mathrm{~d} \tau \\
\Rightarrow-k(\nu, t)-p(t) s(\nu, t) & =\bar{w}(t)-\bar{z}(\nu, t)-\int_{t}^{\infty} c(\nu, \tau) e^{-R} \mathrm{~d} \tau
\end{aligned}
$$


which is the lifetime budget constraint (16), written here in the more general form with age-dependent transfers/taxes $z(\nu, t)$. For the integration of the left-hand side in the last step, we used $\exp (-R(t, t))=1$ and Equation (7).

Then, the individual consumption level follows from solving the KeynesRamsey rule for $c$, which gives

$$
c(\nu, \tau)=c(\nu, t) \exp \left(\int_{t}^{\tau}(r(\tau)-\rho) \mathrm{d} \tau\right),
$$

and substituting this into the lifetime budget equation,

$$
\begin{aligned}
k(\nu, t)+p(t) s(\nu, t)+\bar{w}(t)-\bar{z}(\nu, t) & =\int_{t}^{\infty} c(\nu, t) e^{\int_{t}^{\tau}[r(\tilde{t})-\rho] \mathrm{d} \tilde{t}} e^{-R(t, \tau)} \mathrm{d} \tau= \\
& =c(\nu, t) /(\rho+\phi) .
\end{aligned}
$$

Hence, individual consumption is a fixed fraction of wealth.

\section{A.3 Aggregate solution}

We derive the aggregate quantities for general age-dependent transfers $z(\nu, t)$, and then simplify them for uniform transfers to obtain the relations given in the main text.

The aggregate consumption level $C(t)$ for general transfers is obtained directly from aggregation of Equation (17), as given by Equation (18) in the main text.

The dynamics of the total capital stock (19) are obtained by applying Leibniz' rule to

$$
K(t)=\int_{-\infty}^{t} k(\nu, t) \phi e^{\phi(\nu-t)} \mathrm{d} \nu,
$$

replacing $\dot{k}$ by its expression from the individual budget constraint 10 , and using Equation (6) for aggregate changes in resource ownership:

$$
\begin{aligned}
\dot{K}(t) & =\underbrace{k(t, t)}_{=0} \phi e^{\phi(t-t)}-0+\int_{-\infty}^{t} \frac{\mathrm{d}}{\mathrm{d} t}\left[k(\nu, t) \phi e^{\phi(\nu-t)}\right] \mathrm{d} \nu= \\
& =-\phi K(t)+\int_{-\infty}^{t} \dot{k}(\nu, t) \phi e^{\phi(\nu-t)} \mathrm{d} \nu= \\
& =w(t)+r(t) K(t)+[1-T(t)] \sigma b(t) S-p(t) \sigma S+ \\
& +p(t) \underbrace{\left[\phi S-\int_{-\infty}^{t} \dot{s}(\nu, t) \phi e^{\phi(\nu-t)} \mathrm{d} \nu\right]}_{=\bar{E}=\sigma S}-C(t)-\underbrace{\int_{-\infty}^{t} z(\nu, t) \phi e^{\phi(\nu-t)} \mathrm{d} \nu}_{=-T(t) b(t) \sigma S+I_{A}}= \\
& =w(t)+r(t) K(t)+\sigma b(t) S-I_{A}-C(t) .
\end{aligned}
$$


The government budget constraint (11) was used in the last step, to the effect that the aggregate result does not directly depend on the transfer scheme $z(\nu, t)$. However, it may have an indirect effect via prices, stock levels and consumption.

Similarly, we derive the dynamics of aggregate consumption, first for the case of general, age-dependent transfers $z(\nu, t)$ :

$$
\begin{aligned}
\dot{C}(t) & =c(t, t) \phi e^{\phi(t-t)}-0+\int_{-\infty}^{t} \frac{\mathrm{d}}{\mathrm{d} t}\left[c(\nu, t) \phi e^{\phi(\nu-t)}\right] \mathrm{d} \nu= \\
& =\phi(\rho+\phi)[h(t, t)]-\phi C(t)+\underbrace{\int_{-\infty}^{t} \dot{c}(\nu, t) \phi e^{\phi(\nu-t)} \mathrm{d} \nu}_{=(r(t)-\rho) C(t)}= \\
& =[r(t)-\rho] C(t)-\phi(\rho+\phi)[K(t)+p(t) S-\bar{Z}(t)+\bar{z}(t, t)] .
\end{aligned}
$$

The first equality follows from Leibniz' rule. For the second, $c(t, t)=(\rho+$ $\phi)[k(t, t)+p(t) s(t, t)+h(t, t)]=(\rho+\phi)[h(t, t)]$ is used. In the third step, $\phi C(t)$ is replaced using Equation (18). Alternatively, we could have directly differentiated Equation (18) and used that, by Leibniz' rule, $\dot{H}=(r+\phi) H-$ $w+Z+\phi(\bar{Z}-\bar{z}(t, t))$. We thus obtain

$$
\frac{\dot{C}(t)}{C(t)}=r(t)-\rho-\phi(\rho+\phi) \frac{K(t)+p(t) S(t)-\bar{Z}(t)+\bar{z}(t, t)}{C(t)} .
$$

This is the general result (20|) used in Section 3.3. For the special case of uniform, age-independent transfers,

$$
z(\nu, t)=z_{u}(t)
$$

we have $\bar{Z}(t)=\bar{z}(t, t)=\bar{z}_{u}(t)$ and Equation (20) simplifies to Equation 20 in the main section.

\section{A.4 Socially optimal solution}

The social planner solution represents a normative benchmark to evaluate the adequacy of the climate policies discussed in the article. The application of the approach of Calvo and Obstfeld (1988) to the social planner problem is as in Edenhofer et al. (2013), we restate it here to make this article selfcontained.

We here define social welfare as the (discounted) preference satisfaction of the heterogeneous households. The socially optimal rate of pure time preference is assumed to equal the private rate of pure time preference for simplicity. 
Social welfare $V$ at time $t$ is defined as follows:

$$
\begin{aligned}
V(t) & =\int_{-\infty}^{t}\left\{\int_{t}^{\infty} \ln c(\nu, \tau) e^{-\rho \tau} \phi e^{-\phi(\tau-\nu)} \mathrm{d} \tau\right\} \mathrm{d} \nu \\
& +\int_{t}^{\infty}\left\{\int_{\nu}^{\infty} \ln c(\nu, \tau) e^{-\rho \tau} \phi e^{-\phi(\tau-\nu)} \mathrm{d} \tau\right\} \mathrm{d} \nu .
\end{aligned}
$$

which is the social welfare function considered by Calvo and Obstfeld (1988) when the private equals the social rate of pure time preference.

We now apply the two-step procedure of Calvo and Obstfeld (1988) for social planner problems with overlapping generations to determine the socially optimal level of aggregate capital and consumption: (i) the optimal static distribution is derived for every point in time, (ii) the intertemporally optimal solution is chosen independently.

(i) Define $U(C(t))$ as the solution to the static maximization problem:

$$
\begin{aligned}
U(C(t)) & =\max _{\{c(\nu, t)\}_{\nu=-\infty}^{t}} \int_{-\infty}^{t} \ln c(\nu, t) \phi e^{-\phi(t-\nu)} \mathrm{d} \nu \\
\text { subject to: } C(t) & =\int_{-\infty}^{t} c(\nu, t) \phi e^{-\phi(t-\nu)} \mathrm{d} \nu .
\end{aligned}
$$

The solution to this problem is:

$$
U(C(t))=\ln (C(t)) .
$$

The result is true since all agents have the same utility function. Intuitively, distributing the fixed amount $C(t)$ among all living agents at time $t$ thus makes giving an equal share to each of them optimal. As population is normalized to 1 , the share given to the individual equals the total amount of consumption, $C(t)$, so that total utility is $\ln (C(t))$.

Proof. Solving the maximization problem (47) with integral constraint (48) and writing $\lambda$ as multiplier to that constraint, one obtains the current-value Hamiltonian

$$
H_{c}=\phi \ln c(\nu, t)+\lambda \phi c(\nu, t)
$$

and thus finds the first-order conditions:

$$
\begin{aligned}
\frac{\partial H_{c}}{\partial c} & =\frac{\phi}{c(\nu, t)}+\lambda \phi=0 \\
(t-\nu) \lambda & =(t-\nu) \lambda-\dot{\lambda} .
\end{aligned}
$$

The last equation implies that $\lambda$ is constant, so from Equation 49 it follows that the optimal $c(\nu, t)$ is constant for all $\nu$, too. Setting $c(\nu, t)=c^{\prime}(t)$ in Equation (48) implies

$$
C(t)=c^{\prime}(t) .
$$

Inserting this in Equation (47) gives the result. 
(ii) The intertemporal maximization problem of the social planner is then the following problem:

$$
\begin{aligned}
\max _{C(t)} & \int_{t=0}^{\infty} U(C(t)) e^{-\rho t} d t \\
\text { with } \quad U(C) & =\ln (C) \\
\text { s.t. } \quad \dot{K}(t) & =F\left(K(t), L(t), A_{0} E_{0}\right)-\delta K(t)-I_{A}^{*}-C(t) .
\end{aligned}
$$

The corresponding rule for socially optimal aggregate consumption growth is thus the Keynes-Ramsey rule

$$
\frac{\dot{C}(t)}{C(t)}=F_{K}(K(t), L(t), A(t) \bar{E}(t))-\delta-\rho .
$$

We therefore take the Keynes-Ramsey level of consumption and capital as the reference point for social optimality in the main part of the paper.

\section{A.5 Formal proof of the portfolio effect}

Proof of Theorem 1. The idea of the proof is to compare the steady state of the decentralized equilibrium for two different auctioned shares of permits (or tax rates on resource extraction revenues): It will be shown that although for a fixed capital stock, consumption, and thus social welfare, is lower with a higher auctioned share, both the consumption and the capital stock are higher in the steady state, the higher the auctioned share is. This is illustrated in Figure 1 .

Consider two auctioning shares, $0 \leq T_{1}<T_{2} \leq 1$. Let the steady state defined by Equations (22) and (23) for the two shares be denoted by $\left(K^{1 *}, C^{1 *}\right)$ and $\left(K^{2 *}, C^{2 *}\right)$. The superscripts 1 and 2 also indicate the respective cases for the parabola and the hyperbola. From the definition of social welfare given in Section 3 , it is sufficient to prove that

$$
C^{1 *}<C^{2 *} \text {. }
$$

The parabola (22) (defined by $\dot{K}=0$ ) is not affected by the auctioned share. However the hyperbola (23) (defined by $\dot{C}=0$ ) changes: It is equivalent to the following expression

$$
C_{H}^{i}(K)=\phi \frac{\rho+\phi}{r(K)-\rho}\left\{K+\frac{\sigma b_{0}(K) S_{0}}{r(K)}-T_{i} \frac{\sigma b_{0}(K) S_{0}}{r(K)}\right\}
$$

for $i=1,2$. As the last term in the curly bracket is negative, it follows that $C_{H}^{2}(K)<C_{H}^{1}(K)$ for all $K \in\left[0, K^{k r}\right]$. In Figure 1, the hyperbola for $T_{2}$ is below that for $T_{1}$. 
For any $K<K^{1 *}$, we also have $C_{H}^{1}(K)<C_{P}^{1}(K)$ and $C_{P}^{1}(K)=C_{P}^{2}(K)$ since the parabola is independent of $T$. Hence $C_{H}^{2}(K)<C_{P}^{2}(K)$ for $K<$ $K^{0 *}$. Moreover, $C_{H}^{i}(K)$ is positive for all $K \leq K^{k r}$, and thus tends to $+\infty$ as $K$ approaches $K^{k r}$. Thus the (non-trivial) intersection of parabola and hyperbola for $T_{2}$ must occur at a capital stock $K^{2 *}$ with $K^{1 *} \leq K^{2 *}<K^{k r}$. In this interval, $C_{P}(K)$ is increasing in $K$, thus $K^{1 *}<K^{2 *}$ and also $C^{1 *}<$ $C^{2 *}$, as required.

\section{A.6 Dynamical system and portfolio effect for constant car- bon tax}

We first show that a carbon tax needs to be constant for a balanced path to exist. From Equations (19) and (20), we saw that $K(t)=K^{*}, C(t)=C^{*}$ requires $d / d t(A E)=0$ and $d / d t(p S)=0$. From the first condition and Equation 12 follows that the government needs to set $I_{A}=1 / \theta(-\dot{E} / E)$ on a balanced path. The second condition can be rewritten with the help of Equation $(15(b)$ as $d / d t[(1-T) b S]=0$. So the government needs to choose $\psi(t)$ such that the following system of differential equations is solved:

$$
\begin{aligned}
\dot{S} / S & =-E / S, \\
\dot{b} / b & =\psi-\dot{S} / S \quad(\text { for }(1-T) b S \neq 0), \\
\dot{b} / b & =\psi+r .
\end{aligned}
$$

The last two conditions are only both satisfied if $\dot{S} / S=-r$, which is constant on the balanced path. From the first equation then follows that

$$
\dot{E} / E=\dot{S} / S=-r .
$$

Furthermore, using the balanced-path conditions $d / d t(A E)=0$ and $\dot{K}=0$ in (33), and again $\dot{E} / E=-r$, we have

$$
\dot{b} / b=\dot{A} / A=-\dot{E} / E=r .
$$

This can only hold simultaneously with the fifth equation above if

$$
\psi=0
$$

We now show that Theorem 1 extends to the case of a constant carbon tax (or long-term permit scheme). For the aggregate dynamics under a 
general carbon tax, we obtained in Section 4.2

$$
\begin{aligned}
\dot{S} & =-E, \\
\dot{p} / p & =r \quad \text { and } \quad p=(1-T) b, \\
\dot{b} / b & =r+\psi \quad \text { with } \quad \psi:=\dot{T} /(1-T), \\
\dot{K} & =F(K, L, A E)-\delta K-I_{A}-C, \\
\dot{C} / C & =r-\rho-\phi(\rho+\phi)(K+p S) / C, \\
\dot{A} & =\theta I_{A} A
\end{aligned}
$$

The first five equations represent the behavior of the private agents, the last equation the government's resource efficiency investment. Assume that the government implements a tax which is constant $(\psi=0)$, implying that $\dot{p} / p=\dot{b} / b=r$. Furthermore, assume that it uses the revenues for R\&D investment that exactly offsets resource extraction, $I_{A}=1 / \theta(-\dot{E} / E)$, so that $A E=$ const. and $\dot{A} / A=-\dot{E} / E$. Then, the essential dynamics of the system are captured by just four differential equations (without the second and the last equation above).

Finally, for simplicity we assume that production can be described by a Cobb-Douglas function, $Y=F(K, L, A E)=K^{\alpha}(A E)^{\beta} L^{(1-\alpha-\beta)}$. Using Equation (33), we then have

$$
\frac{\dot{b}}{b}=\frac{d / d t F_{E}(\cdot)}{F_{E}(\cdot)}=\frac{\dot{A}}{A}+\alpha \frac{\dot{K}}{K} .
$$

The essential dynamical system can now be written as

$$
\begin{aligned}
\dot{S} / S & =-E / S, \\
\dot{E} / E & =\alpha \dot{K} / K-r(K), \\
\dot{K} / K & =[F(K)-\delta K-C+\dot{E} /(\theta E)] / K, \\
\dot{C} / C & =r(K)-\rho-\phi(\rho+\phi)[K+(1-T) \beta F(K) S / E] / C .
\end{aligned}
$$

Substituting (55) into (56) and defining $\epsilon:=E / S$, we obtain

$$
\begin{aligned}
\dot{S} / S & =-\epsilon, \\
\dot{\epsilon} / \epsilon & =\epsilon+\alpha \dot{K} / K-r(K), \\
\dot{K} / K & =[F(K)-\delta K-C-r(K) / \theta] \theta /(\theta K-\alpha), \\
\dot{C} / C & =r(K)-\rho-\phi(\rho+\phi)[K+(1-T) \beta F(K) / \epsilon] / C .
\end{aligned}
$$

The last three equations are a dynamical system in $\epsilon, C$ and $K$. Its fixed point satisfies

$$
\begin{aligned}
\epsilon & =r(K) \\
C & =F(K)-\delta K-r(K) / \theta \\
C & =\phi(\rho+\phi)[K+(1-T) \beta F(K) / r(K)] /[r(K)-\rho] .
\end{aligned}
$$


In the $C$ - $K$-plane, the last two equations describe a parabola and hyperbola as before (cf. Equations $(22)$ and (23)). The fixed point is stable, since the same argument as in Footnote 8 applies (in this case with two jump variables, $C_{0}$ and $\epsilon_{0}=E_{0} / S_{0}$ chosen such that the transversality conditions are met). Thus, the occurence of a macroeconomic portfolio effect under a carbon tax can be proved in a similar way as for the short-term permit case:

Proof of Corollary [2. Similar to the proof of Theorem 1 with Equation (53) modified to

$$
C_{H}^{i}(K)=\phi \frac{\rho+\phi}{r(K)-\rho}\left\{K+\frac{\beta F(K)}{r(K)}-T_{i} \frac{\beta F(K)}{r(K)}\right\} .
$$

\section{References}

Aldy, J. E., Krupnick, A. J., Newell, R. G., Parry, I. W. H., Pizer, W. A., 2010. Designing climate mitigation policy. Journal of Economic Literature 48(4), 903-934.

Asheim, G. B., 2012. A distributional argument for supply-side climate policies. Environmental and Resource Economics 56(2), 239-254.

Ayres, R. U., 1997. Environmental market failures: Are there any local market-based corrective mechanisms for global problems? Mitigation and adaptation strategies for global change 1(3), 289-309.

Bauer, N., Mouratiadou, I., Luderer, G., Baumstark, L., Brecha, R. J., Edenhofer, O., Kriegler, E., 2013. Global fossil energy markets and climate change mitigation - an analysis with ReMIND. Climatic Change pp. 1-14.

Bento, A. M., Jacobsen, M., 2007. Ricardian rents, environmental policy and the double-dividend hypothesis. Journal of Environmental Economics and Management 53(1), 17-31.

Blanchard, O. J., 1985. Debts, deficits, and finite horizons. Journal of Political Economy 93(2), 223-247.

Bovenberg, A. L., 1999. Green tax reforms and the double dividend: an updated reader's guide. International Tax and Public Finance 6(3), 421443.

Bovenberg, A. L., De Mooij, R. A., 1994. Environmental levies and distortionary taxation. The American Economic Review 84(4), 1085-1089. 
Bowles, S., Polania-Reyes, S., 2012. Economic incentives and social preferences: substitutes or complements? Journal of Economic Literature 50(2), $368-425$.

Buiter, W. H., 1989. Debt neutrality, Professor Vickrey and Henry George's single tax. Economics Letters 29(1), 43-47.

Calvo, G. A., Obstfeld, M., 1988. Optimal time-consistent fiscal policy with finite lifetimes. Econometrica 56(2), 411-432.

Carbone, J. C., Morgenstern, R. D., Williams III, R. C., 2012. Carbon taxes and deficit reduction. Working paper.

Ciais, P., Sabine, C., Bala, G., Bopp, L., Brovkin, V., Canadell, J., Chhabra, A., De Fries, R., Galloway, J., Heimann, M., Jones, C., Le Qur, C., Myneni, R., Piao, S., Thornton, P., 2013. Carbon and other biogeochemical cycles. In: Stocker, T., Qin, D., Plattner, G.-K., Tignor, M., Allen, S., Boschung, J., Nauels, A., Xia, Y., Bex, V., Midgley, P. (Eds.), Climate Change 2013: The Physical Science Basis. Contribution of Working Group I to the Fifth Assessment Report of the Intergovernmental Panel on Climate Change, Cambridge University Press.

Clarke, L., Jiang, K., Akimoto, K., Babiker, M., Blanford, G., FisherVanden, K., Hourcade, J.-C., Krey, V., Kriegler, E., Löschel, A., McCollum, D., Paltsev, S., Rose, S., Shukla, P., Tavoni, M., van der Zwaan, B., van Vuuren, D., 2014. Assessing transformation pathways. In: Edenhofer, O., Pichs-Madruga, R., Sokona, Y., Farahani, E., Kadner, S., Seyboth, K., Adler, A., Baum, I., Brunner, S., Eickemeier, P., Kriemann, B., Savolainen, J., Schlömer, S., von Stechow, C., Zwickel, T., Minx, J. (Eds.), Climate Change 2014: Mitigation of Climate Change. Contribution of Working Group III to the Fifth Assessment Report of the Intergovernmental Panel on Climate Change, Cambridge University Press, Cambridge.

Dasgupta, P., Heal, G., 1979. Economic Theory and Exhaustible Resources. Cambridge University Press, Cambridge.

Edenhofer, O., Jakob, M., Creutzig, F., Flachsland, C., Fuss, S., Kowarsch, M., Lessmann, K., Mattauch, L., Siegmeier, J., Steckel, J. C., 2014. Closing the emission price gap. submitted.

Edenhofer, O., Mattauch, L., Siegmeier, J., 2013. Hypergeorgism: When is rent taxation as a remedy for insufficient capital accumulation socially optimal? CESifo Working Paper Series 4144.

Fawcett, T., 2010. Personal carbon trading: A policy ahead of its time? Energy Policy 38(11), 6868-6876. 
Feldstein, M. S., 1977. The surprising incidence of a tax on pure rent: A new answer to an old question. Journal of Political Economy 85(2), 349-360.

Finus, M., 2008. Game theoretic research on the design of international environmental agreements: Insights, critical remarks, and future challenges. International Review of Environmental and Resource Economics 2(1), 2967.

Fischer, C., Newell, R. G., 2008. Environmental and technology policies for climate mitigation. Journal of Environmental Economics and Management 55(2), 142-162.

Fleming, D., 1997. Tradable Quotas: Setting Limits to Carbon Emissions. Lean economy papers, Lean Economy Initiative, Elm Farm Research Centre.

Frey, B. S., 1999. Morality and rationality in environmental policy. Journal of Consumer Policy 22(4), 395-417.

Fullerton, D., Metcalf, G. E., 2001. Environmental controls, scarcity rents, and pre-existing distortions. Journal of Public Economics 80, 249-267.

Goulder, L. H., 1995. Environmental taxation and the double dividend: a reader's guide. International Tax and Public Finance 2(2), 157-183.

Groth, C., Schou, P., 2007. Growth and non-renewable resources: The different roles of capital and resource taxes. Journal of Environmental Economics and Management 53(1), 80-98.

Heijdra, B. J., Kooiman, J. P., Ligthart, J. E., 2006. Environmental quality, the macroeconomy, and intergenerational distribution. Resource and Energy Economics 28(1), 74-104.

Hillman, M., 1998. Carbon budget watchers. Town and Country Planning 67,305 .

IPCC, 2014. Summary for policymakers. In: Edenhofer, O., Pichs-Madruga, R., Sokona, Y., Farahani, E., Kadner, S., Seyboth, K., Adler, A., Baum, I., Brunner, S., Eickemeier, P., Kriemann, B., Savolainen, J., Schlömer, S., von Stechow, C., Zwickel, T., Minx, J. (Eds.), Climate Change 2014: Mitigation of Climate Change. Contribution of Working Group III to the Fifth Assessment Report of the Intergovernmental Panel on Climate Change, Cambridge University Press, Cambridge.

Kalkuhl, M., Brecha, R. J., 2013. The carbon rent economics of climate policy. Energy Economics 39, 89-99.

Karp, L., Rezai, A., 2014a. Asset prices and climate policy. Technical report, mimeo. 
Karp, L., Rezai, A., 2014b. The political economy of environmental policy with overlapping generations. International Economic Review 55(3), 711733.

Koethenbuerger, M., Poutvaara, P., 2009. Rent taxation and its intertemporal welfare effects in a small open economy. International Tax and Public Finance 16(5), 697-709.

Mankiw, N. G., 2008. Principles of Economics. Cengage Learning, 5th edition.

Marini, G., van der Ploeg, F., 1988. Monetary and fiscal policy in an optimising model with capital accumulation and finite lives. The Economic Journal 98(392), 772-786.

McKibbin, W. J., 2012. A new climate strategy beyond 2012: lessons from monetary history. The Singapore Economic Review 57(03).

McKibbin, W. J., Wilcoxen, P. J., 2002. Climate change policy after Kyoto: Blueprint for a realistic approach. Brookings Institution Press.

McKibbin, W. J., Wilcoxen, P. J., 2007. A credible foundation for longterm international cooperation on climate change. In: Architectures for agreement: addressing global climate change in the post-Kyoto world, Cambridge University Press Cambridge.

Meinshausen, M., Meinshausen, N., Hare, W., Raper, S. C. B., Frieler, K., Knutti, R., Frame, D. J., Allen, M. R., 2009. Greenhouse-gas emission targets for limiting global warming to 2 C. Nature 458(7242), 1158-1162.

Petrucci, A., 2006. The incidence of a tax on pure rent in a small open economy. Journal of Public Economics 90(4-5), 921-933.

Segal, P., 2011. Resource rents, redistribution, and halving global poverty: The resource dividend. World Development 39(4), 475-489.

Siegmeier, J., Mattauch, L., Franks, M., Klenert, D., Schultes, A., Edenhofer, O., 2014. A public economics perspective on climate policy: Six interactions that may enhance welfare. Mimeo.

Sinclair, P. J. N., 1994. On the optimum trend of fossil fuel taxation. Oxford Economic Papers 46, 869-877.

Starkey, R., 2012a. Personal carbon trading: A critical survey part 1: Equity. Ecological Economics 73, 7-18.

Starkey, R., 2012b. Personal carbon trading: A critical survey part 2: Efficiency and effectiveness. Ecological Economics 73, 19-28. 
Stavins, R., Zou, J., Brewer, T., Conte Grand, M., den Elzen, M., Finus, M., Gupta, J., Höhne, M.-K., N. amd Lee, Michaelowa, A., Paterson, M., Ramakrishna, K., Wen, G., Wiener, J., Winkler, H., 2014. International cooperation: Agreements and instruments. In: Edenhofer, O., PichsMadruga, R., Sokona, Y., Farahani, E., Kadner, S., Seyboth, K., Adler, A., Baum, I., Brunner, S., Eickemeier, P., Kriemann, B., Savolainen, J., Schlömer, S., von Stechow, C., Zwickel, T., Minx, J. (Eds.), Climate Change 2014: Mitigation of Climate Change. Contribution of Working Group III to the Fifth Assessment Report of the Intergovernmental Panel on Climate Change, Cambridge University Press, Cambridge.

Stiglitz, J. E., 2014. Reforming taxation to promote growth and equity. Technical report, Roosevelt Institute.

Yaari, M. E., 1965. Uncertain lifetime, life insurance and the theory of the consumer. Review of Economic Studies 32(2), 137-150. 